CZASOPISMO INŻYNIERII LĄDOWEJ, ŚRODOWISKA I ARCHITEKTURY JOURNAL OF CIVIL ENGINEERING, ENVIRONMENT AND ARCHITECTURE

JCEEA, t. XXXIII, z. 63 (4/16), październik-grudzień 2016, s. 375-382

\author{
Bożena ORLIK-KOŻDOŃ${ }^{1}$ \\ Agnieszka SZYMANOWSKA-GWIŻD $\dot{Z}^{2}$ \\ Paweł KRAUSE ${ }^{3}$ \\ Tomasz STEIDL ${ }^{4}$
}

\title{
ANALIZA STANU WILGOTNOŚCIOWEGO ŚCIAN Z CEGLY Z IZOLACJĄ CIEPLNĄ OD WEWNĄTRZ
}

\begin{abstract}
Autorzy podjęli próbę analizy stanu wilgotnościowego ścian z izolacją cieplną od wewnątrz wykonaną z dwóch materiałów izolacyjnych o odmiennych cechach fizycznych. Ich celem jest uzyskanie odpowiedzi na pytania: czy rodzaj materiału izolacyjnego w systemie ociepleń od wewnątrz ścian z cegły wpływa na zawilgocenie warstw przegrody, których i w jakim stopniu? jak zastosowany materiał izolacyjny będzie wpływał na proces wysychania przegrody i reagował na zmienne warunki cieplno-wilgotnościowe otaczających środowisk? Analizowaną ścianą był mur z cegły o grubości $38 \mathrm{~cm}$. Docieplony został materiałem izolacyjnym o grubości $10 \mathrm{~cm}$ w wariancie pierwszym: polistyren ekspandowany (W_1), w wariancie drugim: lekki beton komórkowy (W_2). Ze wstępnych analiz wykonanych w oparciu o założenia normy PN ISO 13788 wynika, że obie przegrody zostały zaprojektowane prawidłowo pod względem uniknięcia rozwoju pleśni na powierzchni wewnętrznej. Dla wariantu drugiego obserwuje się jednak wewnętrzną kondensację pary wodnej ( na styku materiału izolacyjnego oraz ściany), oraz że kondensat nie wyparuje w miesiącach letnich. Szczegółową analizę zachowania się przegrody wykonano w programie WUFI zakładając trzyletni okres pomiarowy (norma PN ISO 13788 pozwala na ocenę tylko dla jednego roku). Uzyskane wyniki wykazują przyrost zawilgocenia w obu wariantach dociepleniowych. W zależności od rodzaju użytego materiału izolacyjnego zmienia się poziom zawartości wilgoci dla poszczególnych warstw i dla wybranych kształtuje się ona na stałym poziomie (mur z cegły) lub charakteryzuje się stałą tendencja zmian (lekki beton komórkowy).
\end{abstract}

Słowa kluczowe: docieplanie od wewnątrz, zawartość wilgoci, lekki beton komórkowy, polistyren ekspandowany

\footnotetext{
1 Autor do korespondencji / corresponding author: Bożena Orlik-Kożdoń, Politechnika Śląska, Katedra Budownictwa Ogólnego i Fizyki Budowli, ul. Akademicka 5, 44-100 Gliwice, tel. 32237 2303; Bozena.Orlik@polsl.pl

2 Agnieszka Szymanowska-Gwiżdż; Politechnika Śląska, Katedra Budownictwa Ogólnego i Fizyki Budowli, ul.Akademicka 5, 44-100 Gliwice, tel. 32 237 2303; Agnieszka.Szymanowska-Gwizdz@polsl.pl

3 Paweł Krause; Politechnika Śląska, Katedra Budownictwa Ogólnego i Fizyki Budowli, ul. Akademicka 5, 44-100 Gliwice, tel. 32237 2303; Pawel.Krause@polsl.pl

4 Tomasz Steidl; Politechnika Śląska, Katedra Budownictwa Ogólnego i Fizyki Budowli, ul. Akademicka 5, 44-100 Gliwice, tel. 32237 2303; Tomasz.Steidl@ polsl.pl
} 


\section{Wprowadzenie}

W literaturze można znaleźć sporo opisów metodologii projektowania docieplenia od strony wewnętrznej $[3,12]$. Wiele publikacji ma charakter czysto praktyczny i z powodzeniem może służyć w praktyce inżynierskiej $[8,13,16]$. Podane są tam rozwiązania graficzne detali projektowych oraz podstawowe informacje dotyczące doboru grubości i rodzaju izolacji z równoczesnym podaniem ogólnych wskazówek technologicznych. Wytyczne te wydają się być niewystarczające w sytuacji kompleksowej analizy cieplno-wilgotnościowej projektu docieplenia całego budynku o złożonej geometrii i programie funkcjonalnoużytkowym. W pracach $[4,15]$ przedstawiono całą procedurę projektowania docieplenia budynków istniejących, użyteczności publicznej o znamionach historycznych. Obejmowała ona zarówno złożone modelowanie całej przegrody w kontekście procesów cieplno-wilgotnościowych jak również pomiar wybranych parametrów fizycznych (temperatura, wilgotność) w wybranych punktach przegrody i pomieszczeniu, w którym się ona znajdowała. Wyniki badań i symulacji posłużyły do walidacji modelów procesów transportowych, które wykorzystano $\mathrm{w}$ modelowaniu [1,11]. Wiele $\mathrm{z}$ przedstawionych badań prowadzonych było przez kilka lat, aby móc precyzyjnie ocenić poprawność wykonanych działań $[5,7]$. Analizie poddane zostały budynki o dużych walorach zabytkowych, o charakterze usługowym. W przypadku budynków mieszalnych jednorodzinnych, zamieszkania zbiorowego, ocieplanie przegród od wewnątrz jest własną inicjatywą właściciela. Pociąga to za sobą duże konsekwencje, spowodowane wyborem ogólnodostępnych, tanich materiałów izolacyjnych.

Autorzy podjęli próbę analizy stanu wilgotnościowego ścian z izolacją cieplną od wewnątrz wykonaną z dwóch materiałów izolacyjnych o odmiennych cechach fizycznych (wariant W_1: ocieplenie polistyrenem ekspandowanym o gr. $10 \mathrm{~cm}, \mathrm{~W} \_2$ : ocieplenie lekkim betonem komórkowym o gr. $10 \mathrm{~cm}$ ). Dane materiałowe przedstawiono $\mathrm{w}$ tab. 1.

Należy przy tym stwierdzić, że obliczeniowe analizy stanu wilgotnościowego przegród są zawsze obarczone sporym błędem i nikt nie oczekuje dużej dokładności odpowiedzi, stąd autorów interesowało głównie określenie ogólnego trendu procesu; mniejszą wagę przywiązywano do wyników ilościowych.

\section{Analizy symulacyjne zachowania się przegród docieplanych od wewnątrz}

\subsection{Założenia przyjęte do analizy}

W celu uzyskania odpowiedzi na postawione pytania wykonano obliczenia symulacyjne za pomocą programu WUFI. Oparty jest on na układzie nieliniowych równań różniczkowych cząstkowych, opisujących niestacjonarny sprzężony transport ciepła i wilgoci w materiałach budowlanych. Program ma własną bazę danych materiałowych, obejmującą podstawowe rodzaje wyrobów budowlanych. 
Tab. 1. Początkowa zawartość wilgoci materiałów

Tab. 1. Initial moisture content of materials

\begin{tabular}{|c|c|c|c|c|c|}
\hline $\mathrm{Nr}$ & Materiał/Warstwa & $\begin{array}{c}\text { Grubość } \\
{[\mathrm{m}]}\end{array}$ & $\mu[-]$ & $\begin{array}{c}\lambda \\
{[\mathrm{W} / \mathrm{mK}]}\end{array}$ & $\begin{array}{c}\text { Woda/ } \\
\text { Zawartość } \\
{\left[\mathrm{kg} / \mathrm{m}^{3}\right]}\end{array}$ \\
\hline 1 & Tynk zewnętrzny & 0,01 & 19 & 0,8 & 216 \\
\hline 2 & $\begin{array}{c}\text { Mur z cegły peł- } \\
\text { nej(historycznej) }\end{array}$ & 0,38 & 15 & 0,60 & 98 \\
\hline 3 & $\begin{array}{c}\text { Tynk cementowo- } \\
\text { wapienny }\end{array}$ & 0,02 & 19 & 0,8 & 144 \\
\hline 4 & $\begin{array}{c}\text { Styropian }(\lambda-0,04, \rho-12 \\
\left.\text { kg/m }{ }^{3}\right)\end{array}$ & 0,1 & 45 & 0,04 & 0,1 \\
\hline 5 & $\begin{array}{c}\text { Lekki beton komórkowy } \\
\left(\lambda-0,042, \rho-115 \mathrm{~kg} / \mathrm{m}^{3}\right)\end{array}$ & 0,1 & 4,0 & 0,042 & 7.9 \\
\hline 6 & $\begin{array}{c}\text { Wyprawa tynkar- } \\
\text { ska/styropian }\end{array}$ & 0,003 & 50 & 0,87 & 324 \\
\hline 6 & $\begin{array}{c}\text { Wyprawa tynkarska/lekki } \\
\text { beton komórkowy }\end{array}$ & 0,003 & 23 & 0,87 & 405 \\
\hline
\end{tabular}

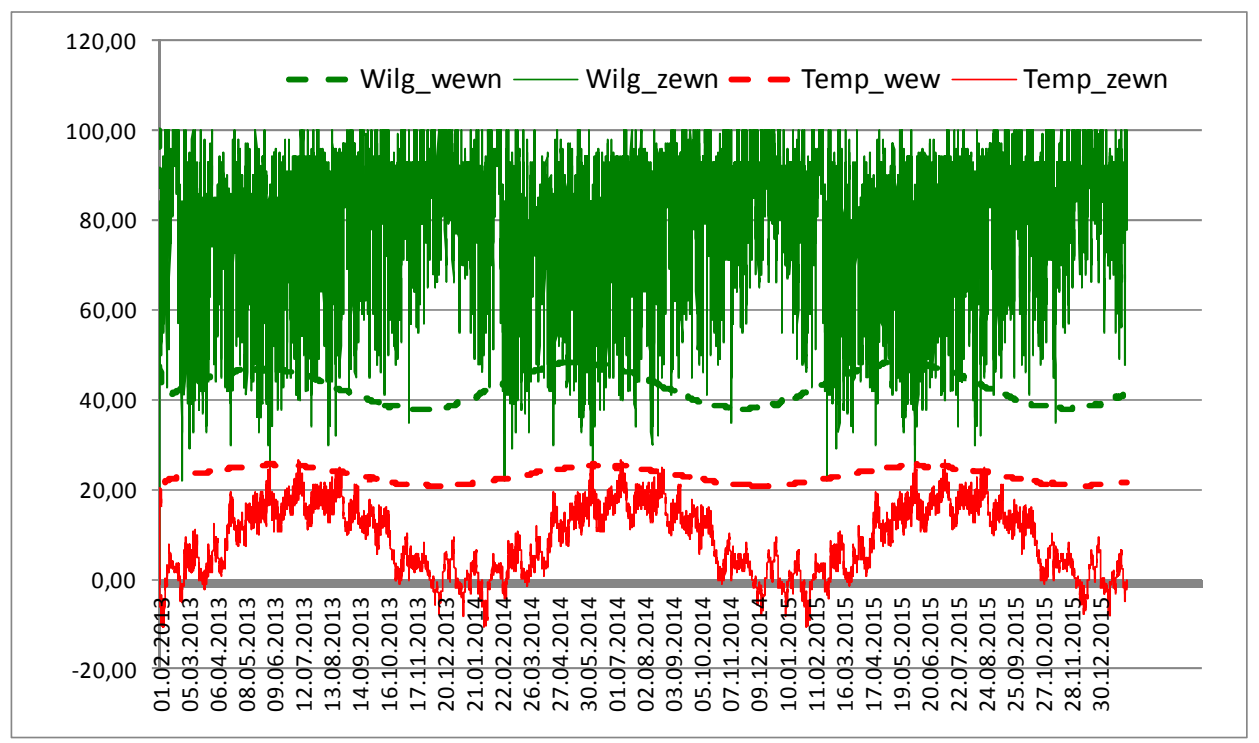

Rys. 1. Profil temperatury i wilgotności względnej przyjęty do analizy

Fig. 1. Profile of temperature and relative humidity adopted for the analysis

Na potrzeby obliczeń przyjęto parametry klimatu zewnętrznego (rys. 1) stacja meteo Kraków (ograniczona baza klimatyczna w programie WUFI). Wpływ klimatu wewnętrznego uwzględnia się przez zadeklarowaną temperaturę 
i wilgotność względną powietrza, z możliwością wprowadzenia ich sinusoidalnej zmienności $\mathrm{w}$ okresie roku. $\mathrm{W}$ pomieszczeniach założono temperaturę zmieniającą się w sposób ciągły od $20^{\circ} \mathrm{C}$ w zimie do $24^{\circ} \mathrm{C}$ w lecie oraz wilgotność względną powietrza zmieniającą się od $35 \%$ w okresie zimowym do $65 \%$ w okresie letnim.

\subsection{Wyniki analizy i komentarz}

Wyniki obliczeń przebiegu wysychania ścian o założonej wilgotności początkowej przedstawiono $\mathrm{w}$ wybranych płaszczyznach przegrody na rys. 2-4. W modelowaniu założono 3-letni okres monitorowania przegrody(start luty 2013). Na wykresach na osi poziomej podano czas, na osi pionowej zawartość wilgoci w murze w kilogramach na metr sześcienny.

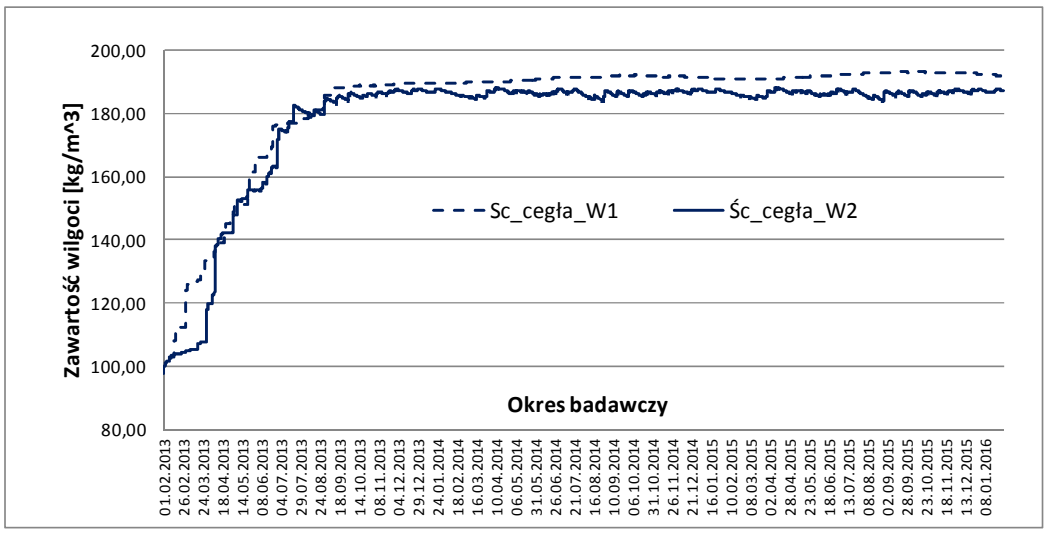

Rys. 2 . Zawartość wilgoci w warstwie cegły dla wariantu W_1 i W_2

Fig. 2. The moisture content of the brick layer for variant $W_{-} 1$ and $W_{-} 2$

Z analizy wykresu (rys. 2) obrazującego zawartość wilgoci w warstwie cegły dla poszczególnych wariantów obserwujemy podobny poziom zawilgocenia. Dla wariantu W_2, (ocieplenie lekkim betonem komórkowym), zawilgocenie choć na stałym poziomie ulega niewielkim wahaniom - poszarpany, nieregularny wykres. Spowodowane jest to właściwościami samego materiału ociepleniowego i jego dużej sorpcyjności. Ta cecha powoduje duże zmiany w całym przekroju przegrody i skoki wilgotności w pozostałych warstwach tej przegrody w granicach: $10 \div 12 \mathrm{~kg} / \mathrm{m}^{3}$.

Styropian z uwagi na swoje parametry dyfuzyjne stanowi dużą blokadę dla migrującej wilgoci. Kumuluje się ona w warstwie tyku znajdującego się pomiędzy styropianem a murem $\mathrm{z}$ cegły. Zawartość wilgoci w tej warstwie jest na poziomie $215 \mathrm{~kg} / \mathrm{m}^{3}$, co stanowi około $10 \%$ jej ciężaru (rys. 3). 


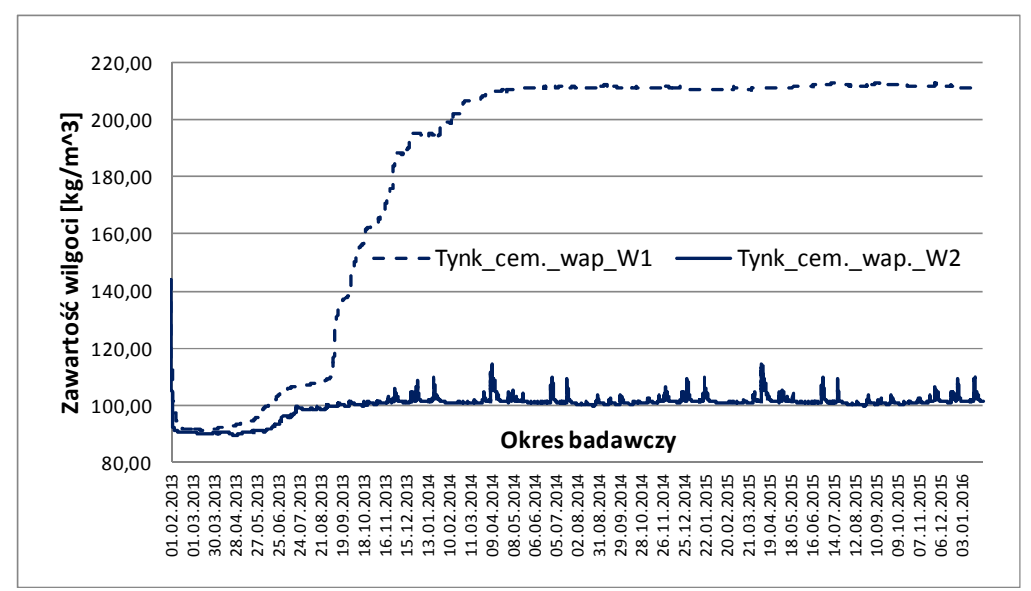

Rys. 3. Zawartość wilgoci w tynku (warstwa pomiędzy cegłą a styropianem/lekkim betonem komórkowym)

Fig. 3. Moisture content in plaster (a layer between the brick and insulation with polystyrene/lightweight cellular concrete)

Dla wariantu W_2 zawilgocenie tej warstwy jest znacznie mniejsze i jest na poziomie $100 \mathrm{~kg} / \mathrm{m}^{3} \mathrm{z}$ chwilowymi skokami. Dodać należy, że dla obu przypadków był to ten sam tynk cementowo-wapienny. Tak więc, to nie jego cechy fizyczne miały bezpośredni wpływ na stan higrotermiczny tej warstwy, ale sąsiadujące materiały izolacyjne. W układzie ściany ocieplonej lekkim betonem komórkowym, to warstwa betonu przejmuje głównie obciążenie związane z migracją wilgoci.

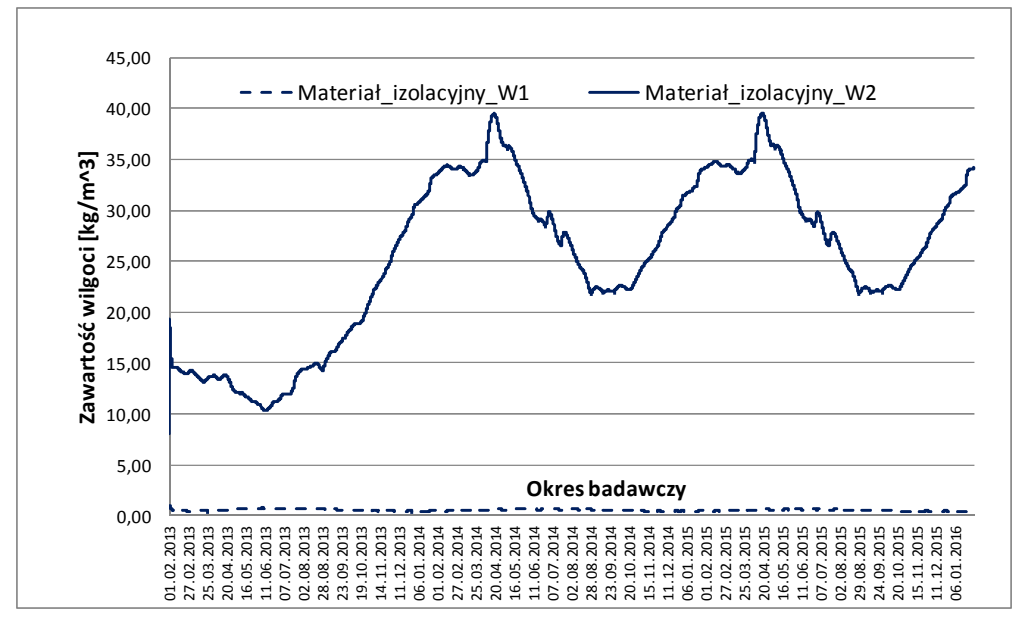

Rys. 4. Zawilgocenie w warstwie styropianu W_1 i lekkiego betonu W_2

Fig. 4. Moisture in the layer of polystyrene and concrete light W_1 W_2 
W procesach transportu, np. przy wysychaniu elementu, bardzo rzadko mamy do czynienia z przemieszczającym się do wnętrza równomiernym frontem wysychania, objawiającym sie całkowitym wyschnięciem powierzchni zewnętrznej i cofnięciem się powierzchni odparowywania w głąb elementu. W przypadku betonu komórkowego jego sorpcyjność intensywnie wzrasta przy wilgotności względnej powietrza powyżej $75 \%$. W procesie sorpcji pary wodnej przy wysokiej wilgotności materiału może wystąpić kondensacja kapilarna. Kondensująca wilgoć znajduje się w stanie słabo związanym, co zaznacza się szybką migracją i wzrostem zawilgocenia materiału. $Z$ uwagi na niewielką różnicę w krzywej histerezy sorpcji i desorpcji dla betonu komórkowego, potrafi on szybko wrócić do równowagi sorpcyjnej. Duża sorpcyjność materiału i jego szybka redystrybucja wilgoci sprawia, że jest on czuły na wahania i zmiany wilgotności. Widoczne jest to w analizie numerycznej (poszarpany wykres) (rys. 4). $\mathrm{Z}$ badan przedstawionych $\mathrm{w}$ pracy [14] wynika jednak, że zdolność pochłaniania wilgoci i rozprowadzania jej na całej powierzchni płyty niesie za sobą konsekwencje. Zaobserwowano, że dla wilgotności względnej większej niż 70\% zmiana przewodności cieplnej dla tego materiału jest w granicach 70\%. Różne wielkości wzrostu współczynnika $\lambda$ dla danego rodzaju materiału przy tej samej wilgotności wynikają bezpośrednio ze struktury i wielkości porów w danym materiale oraz sorpcyjności poszczególnych materiałów. Porównanie wielkości wpływu temperatury i wilgotności na przewodność cieplną pozwala stwierdzić, iż to wilgotność ma wiodący wpływ na wartość współczynnika $\lambda$, gdyż wzrost tego współczynnika spowodowany wzrostem wilgotności jest bardzo duży, kilkukrotnie większy niż wzrost spowodowany zmianą temperatury otoczenia [14].

Dla styku ściany z polistyrenem ekspandowanym EPS obserwujemy tendencję blokowania wpływu środowiska wewnętrznego. Założeniem tego typu rozwiązania jest ograniczenie wnikania wilgoci w strukturę ściany, i należałoby sądzić, że materiał ten zachowuje się zgodnie $\mathrm{z}$ założonym rozwiązaniem. Przyjmuje się, że wilgotność sorpcyjna tego materiału jest prawie zerowa. Niemniej jednak może on ulegać zawilgoceniu, co wykazują badania przedstawione w pracach $[6,10]$. Dla styropianu EPS o gęstości $15 \mathrm{~kg} / \mathrm{m}^{3}$ (jak również innych izolatorów cieplnych) zaobserwowano zróżnicowany wzrost wilgotności objętościowej po cyklach starzeniowych na poziomie 57\% (dlaXPS - 1\%). Autorzy nie określili jednak ilości cykli, ale należy sądzić, że jest to okres dłuższy od założonego w symulacjach (3 lata) i badaniach.

\section{Wnioski końcowe}

Przedstawiony artykuł miał między innymi na celu ukazanie złożoności samego procesu projektowania docieplenia jak i funkcjonowania konkretnych materiałów izolacyjnych w rzeczywistych warunkach eksploatacyjnych. Jak się okazuje dla dwóch typów wyrobów- (popularnych w renowacji cieplnej budynków z cegły na Górnym Śląsku) trudno jednoznacznie udzielić odpowiedzi, które z rozwiązań jest lepsze. Większość problemów skupia się przy ograniczeniu 
ryzyka kondensacji. Za poprawne uznaje się, sytuacje, w których mimo pojawienia się kondensatu, przegroda wysycha w sezonie letnim. Ta jednak ciągła aktywność przegrody i brak stabilizacji higrotermicznej przekłada się bezpośrednio na trwałość całej przegrody i jej poszczególnych warstw. Badania przedstawione $w$ pracach $[2,9]$ wykazały, że w przypadku długotrwałego zawilgocenia styropianu, obserwowany jest brak spójności i wyodrębnianie się poszczególnych ziaren. W przypadku betonów komórkowych o niskiej gęstości, proces utraty parametrów mechanicznych na skutek zawilgocenia jest znacznie szybszy. Nadmienić należy, że w przypadku prac dociepleniowych, ich głównym założeniem jest poprawa izolacyjności przegrody i ograniczenie strat ciepła. W zawilgoconym materiale następuje intensyfikacja transportu ciepła i wzrost przewodności cieplnej materiału. Autorzy pozwalają sobie postawić tezę, że żadne z przedstawionych i powszechnie stosowanych rozwiązań izolacyjnych nie powinno być stosowane $\mathrm{w}$ przedmiotowych budynkach $\mathrm{z}$ uwagi na nieprawidłowe wg. Autorów zachowanie muru.

\section{Literatura}

[1] Fechner, H., Häupl P., Stopp H., and Strangfeld P. Measurements and numerical simulation of the heat and Moisture transfer in envelope parts of buildings. Proceedings Of the International Conference on Thermophysical Properties of Materials, Singapore, 1999.

[2] Gnip J., Korsulis V., Vejelis S., Vaitikus S.: Long-term water absorption of expanded polystyrene boards, www.psu.edu.

[3] Gonçalves, M.D.. 2003. Insulating solid masonry walls." Ninth conference on building science and technology, Ontario Building Envelope Council, Vancouver, bc, pp. 171-181.

[4] Hens, H. 1998. Performance prediction for masonry walls With inside insulation using calculation procedures and Laboratory testing. Journal of Thermal Envelope and Building Science 22:32-48.

[5] Kloseiko P., Arumagi E., Kalamees T.; Hygrothermal performance of internally insulated brick wall in cold climate: A case study in a historical school building; Journal of Building Physics March 2015 vol. 38 no. 5 444-464.

[6] Radoń J., Kuncel H., Olesiak J., Problemy cieplno-wilgotnościowe przy renowacji ścian budynków z muru pruskiego, [In:] Acta Scientarum Polonorum, Architektura, Kraków 2006, 45-53.

[7] Rousseau, M.Z., Maurenbrecher A.H.P. 1990. "Rehabilitation of solid masonry walls", Construction practice publication, institute for research in construction (http://irc.nrc-Cnrc.gc.ca /pubs/cp/wal1_e.html). Originally published in "Construction Canada" 32(5), 1990, p. 15-20.

[8] Schöberl H., Hofer R., Lang Ch.: Handbuch thermische Gebäudesanierung Optimale Ausführungsvarianten erstellt im Rahmen des Projekts:,REBE” - Regionale Zusammenarbeit und Wissenstransfer Im Bereich Bioenergie und Energieeffizienz, Landesinnung Bau Niederösterreich, Wien 2012. 
[9] Sedbauer K., Schunck E., Barthel R., Kunzel H. : Flat Roof Construction Manual, GmbH\&Co, 2010.

[10] Slaght R.G., Moisture Measurement in Polyurethane Foam Insulation, Cold Climate Housing Research Center, 2012.

[11] Stopp H., Strangeld P., Fechner H., Häupl P. ; The Hygrothermal Performance of External Walls with Inside Insulation; Buildings VIII/Wall Performance-Practices.

[12] Straube, J.F., and C.J. Schumacher. 2007. Interior Insulation Retrofits of LoadBearing Masonry Walls in Cold CliMates. Journal of Green Buildings2(2):42-50.

[13] Straube J.F., Ueno K., and Schumacher C. ,J. :Building Science Corporation; Measure Guideline:Internal Insulation of Masonry Walls; U.S. Department of Energy, 2012.

[14] Trochonowicz M., Witek B., Chwiej M.: Analiza wpływu wilgotności i temperatury powietrza na wartość współczynnika przewodności cieplnej materiałów termoizolacyjnych stosowanych wewnątrz pomieszczeń, Budownictwo i Architektura 12(4), 2013, pp.165-176.

[15] Wilkinson J., D. De Rose, B. Sullivan and J.F. Straube; Measuring the Impact of Interior Insulation on Solid Masonry Walls In a Cold Climate; Journal of Building Enclosure Design from Summer 2009, pp. 11-17.

[16] www.english-heritage.org.uk/part Energy efficiency and historic buldings; Insulating solid walls. English Heritage.

\title{
ANALYSIS OF THE STATE OF MOISTURE FOR BRICK WALLS WITH INTERNAL INSULATION
}

\begin{abstract}
S u m m a r y
The authors attempted to analyze the humidity condition of walls with thermal insulation from the inside made from two insulation materials of different diffusion resistance factors. The objective of the work was to find answers to the following questions: does the type of insulation material in the applied system of brick walls insulated from the inside have any impact on the humidity level of layers in the envelope and to what degree?; how is the applied insulation material going to influence the process of humidity transfer in the brick wall and how is it going to react to the changing hygrothermal conditions of the surrounding environment? Wall to be analyzed was the brick wall with a thickness of $38 \mathrm{~cm}$ and insulated material thickness $10 \mathrm{~cm}$ under option 1 : expanded polystyrene (W_1), in the second variant: lightweight cellular concrete (W_2). Preliminary analyses based on assumptions PN ISO 13788 shows that both compartments were designed correctly with respect to avoid growth of mold on the surface. For the second variant is observed, however, internal condensation (at the interface between the insulating material and the wall), and that no condensate will evaporate in the summer months. A detailed analysis of the behaviour of the baffles are made in WUFI assuming three-year period (standard PN ISO 13788 allows you to review for just one year).The results obtained demonstrate the growth of moisture in both materials. Depending on the type of insulating material used changes the level of moisture content for each layer and for selected shapes to it on a constant basis (brick wall) or is characterized by a constant trend changes (cellular concrete).
\end{abstract}

Keywords: internal insulation, hygrothermal processes, water content, brick wall

DOI: $10.7862 / \mathrm{rb} .2016 .282$

Przestano do redakcji: $5.05 .2016 r$.

Przyjęto do druku: 20.12.2016 r. 